\title{
Preliminary Data on the Bioturbation Activity of Hediste Diversicolor (Polychaeta, Nereididae) from the Loire Estuary, France
}

\author{
Patrick Gillet ${ }^{*}$, , Mohammed Mouloud ${ }^{1}$, Catherine Mouneyrac $^{1}$, Pablo Simo $^{1}$ and Franck Gilbert ${ }^{2}$ \\ ${ }^{1}$ Equipe de recherche Mer, Molécules, Santé EA 2160. Institut de Biologie et d'Ecologie Appliquée, UCO F-49008 \\ Angers cedex, France \\ ${ }^{2}$ EcoLab, Laboratoire d'Ecologie Fonctionnelle. UMR 5245 F- 31055 Toulouse, France
}

\begin{abstract}
The ragworm Hediste diversicolor (O. F. Müller, 1776) plays a key role in the estuarine water-sediment interface. This scientific project comes under the framework of the International network Nereis Park Experiment gathering 27 laboratories from all over the world. The experiments were carried out concurrently in spring 2007 using a common protocol. In the Loire estuary, the samples were collected in the intertidal zone of the Saint-Nazaire Bridge. During the field experiment, we estimated the surface area of the burrow walls ( $\mathrm{Sb}$ ) value varied from $\mathrm{Sb}=0.26 \mathrm{~m}^{2} . \mathrm{m}^{-2}$ to $2.18 \mathrm{~m}^{2} \cdot \mathrm{m}^{-2}$ (mean $\mathrm{Sb}=0.75 \mathrm{~m}^{2} \cdot \mathrm{m}^{-2}$ ), and the pumping rate $(\mathrm{Pr})$ value from $\operatorname{Pr}=0.91 . \mathrm{d}^{-1} \mathrm{~m}^{-2}$ to $7.71 . \mathrm{d}^{-1} \mathrm{~m}^{-2}$ (mean value $\mathrm{Pr}$ $\left.=2.71 . \mathrm{d}^{-1} \mathrm{~m}^{-2}\right)$. The density and the biomass of $H$. diversicolor populations largely controlled the amount of reworked sediment. In the laboratory, we estimated the pseudo-diffusive mixing, $\mathrm{Db}$ value varied from $\mathrm{Db}=1.2$ to 1.6 (mean $\mathrm{Db}=$ 1.5). The non-local transport ( $\mathrm{r}$ ) from the upper layers to the bottom of the tubes varied from $r=1$ to $7.2(\mathrm{mean} r=4.3)$. A positive relationship could be established between $\mathrm{Db}$ and the temperature while on the contrary a negative relationship could be established between the Db and biomass. It seems that small individuals are more efficient reworkers than big ones.
\end{abstract}

Keywords: Bioturbation, Burrow walls, Pumping rate, Hediste diversicolor, Loire estuary.

\section{INTRODUCTION}

The ragworm Hediste diversicolor (O.F. Müller, 1776) is a widespread species of coastal lagoons and estuaries from Morocco to Scandinavia. $H$. diversicolor is a major link in food webs and has an economic value as bait for fishing in several European countries [1]. In the Loire estuary, the benthic fauna was studied by [2-4]. The population dynamics of $H$. diversicolor was first studied by [5,6]. More recently the populations of $H$. diversicolor were studied in the Authie and Seine estuaries [7-9].

$H$. diversicolor plays a key role in the physical, chemical and biological properties of the marine water-sediment interface. The influence of $H$. diversicolor on biogeochemical processes has been assigned mainly to their sediment reworking and bioirrigation activities. The works on the bioturbation of $H$. diversicolor are not very numerous [1015]. Such studies on $H$. diversicolor were carried out using luminophores [16, 17].

The aim of this work is to gather initial data on the bioturbation activity of $H$. diversicolor in the Loire estuary. During the field experiment, we assessed the surface of the burrow walls and the pumping rate of $H$. diversicolor. In the laboratory, we used a gallery-diffusors model [13] to estimate the pseudo-diffusive mixing and the non-local transport. The experience was carried out in spring 2007

*Address correspondence to this author at the Equipe de recherche Mer, Molécules, Santé EA 2160. Institut de Biologie et d'Ecologie Appliquée, UCO F-49008 Angers Cedex, France; Tel: 332418166 89;

E-mail: patrick.gillet@uco.fr using a common protocol. This project was carried out within the framework of the Nereis Park Experiment, an international network gathering 27 laboratories all over the world.

\section{MATERIAL AND METHODS}

The survey was carried out in 2007 in the Loire estuary. The sampling site is located in the southern part of the Loire estuary (Latitude 47.26406, Longitude -2.16928) close to StNazaire in the polyhaline zone. Specimens of H. diversicolor were collected using a spade at a depth of approximately 25 $\mathrm{cm}$ in the intertidal zone. The samples were collected from the mud sand community and included Heteromastus filiformis, Hydrobia ulvae and Scrobicularia plana (Fig. 1).

The surface sediment $(0-5 \mathrm{~cm})$ was sieved with a $1 \mathrm{~mm}$ mesh with no water being added. Some sieved sediment was saved for Organic Matter $(\mathrm{OM})$ and grain-size distribution analysis. Four core tubes were filled with a $15-\mathrm{cm}$ high column of sieved sediment.

The core tubes had a diameter of $10 \mathrm{~cm}$. The remainder of the cores $(\sim 10 \mathrm{~cm})$ was filled with seawater from the sampling site and the cores were left for a week with aerated seawater under in situ temperature. Twelve individuals were necessary for the experiment. They were weighted and measured (length). Four individuals were introduced in each of the first three cores; the last core, which contained no organisms, served as a control core. The cores were acclimatized in the aerated seawater system for a week (12:12 dark light cycle with an in situ temperature of $\left.17^{\circ} \mathrm{C}\right)$. A suspension of each luminophore dose with a little water 


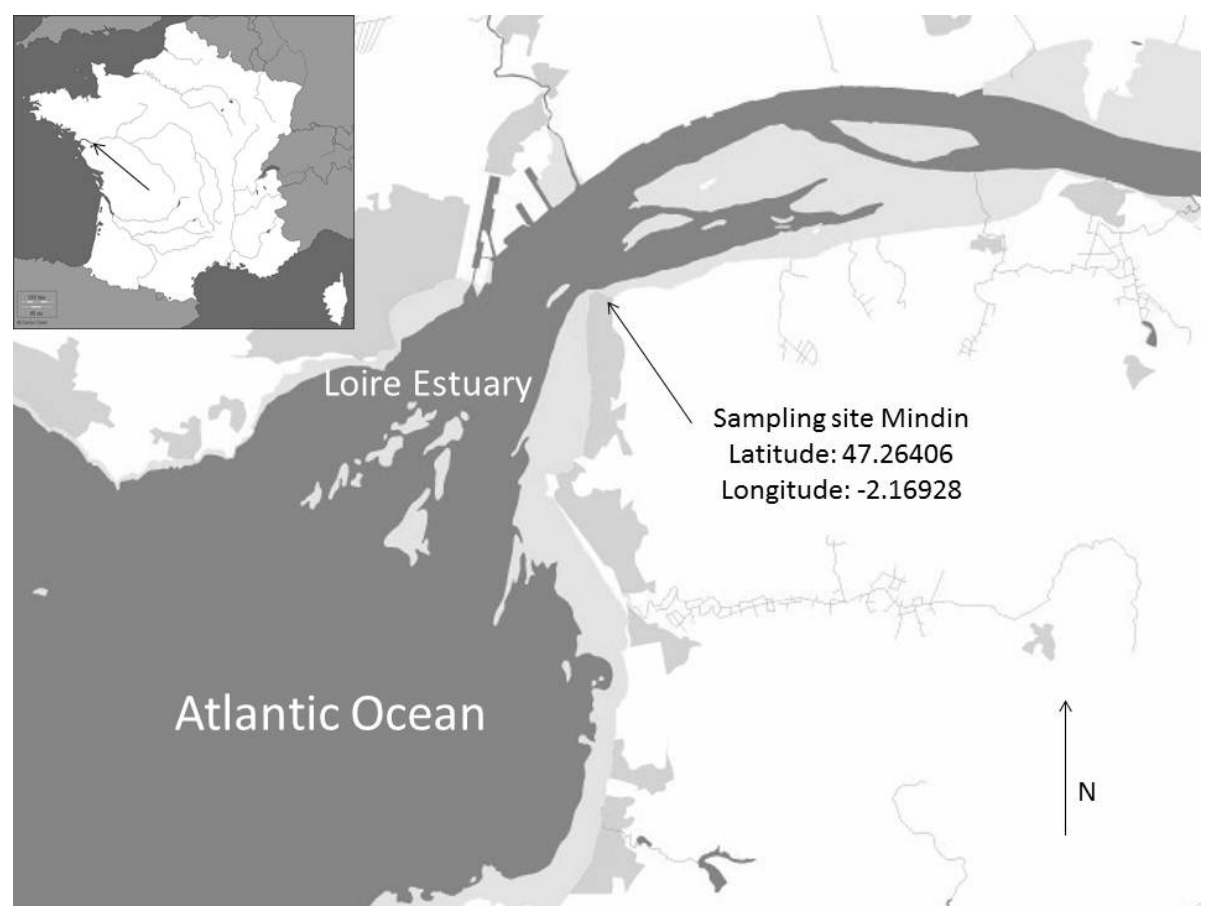

Fig. (1). Location of the sampling site of Hediste diversicolor in the Loire estuary, France.

was added to the overlying water of each core. After 10 days of incubation, the overlying seawater was removed by siphoning. The sediment was sectioned vertically into $0.5 \mathrm{~cm}$-thick layers from the surface down to $2 \mathrm{~cm}$ depth, and then into $1 \mathrm{~cm}$-thick layers down to $15 \mathrm{~cm}$ for Hediste cores (only down to $5 \mathrm{~cm}$ for the control core). Each sediment layer was freeze-dried and then homogenized. We used a gallery-diffusors model [13] with the peudsodiffusive mixing $(\mathrm{Db})$ in the region of intense burrowing activity (surface) and non-local transport (r) from the upper layers down to the tube bottom.

\section{RESULTS AND DISCUSSION}

\section{Field Experiment}

The densities of the population of $H$. diversicolor observed in the Loire estuary varied from $\mathrm{N}=300$ to 2,560 ind. $\mathrm{m}^{-2}$. The mean annual density of $H$. diversicolor was $\mathrm{N}=$ $900 \pm 534$ ind. $\mathrm{m}^{-2}$ with two peaks, the first one with $\mathrm{N}=$

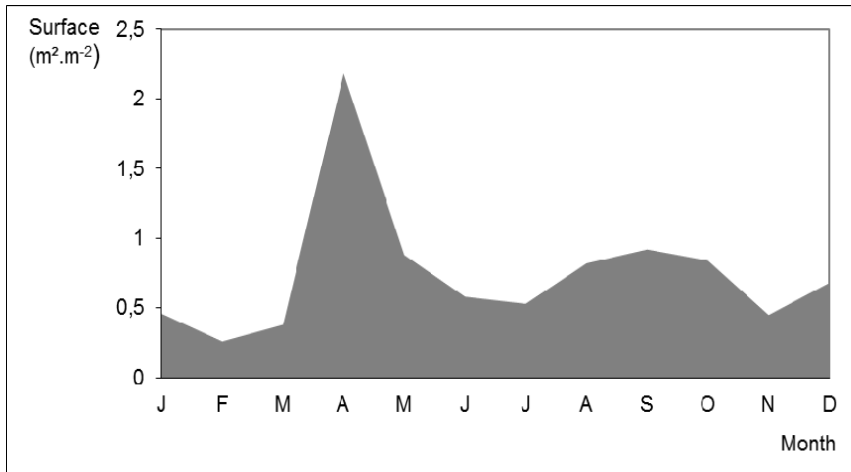

2,560 ind. $\mathrm{m}^{-2}$ in April and the second one with $\mathrm{N}=1,280$ ind. $\mathrm{m}^{-2}$ in September. A decrease in the density was observed in February with $\mathrm{N}=304$ ind. $\mathrm{m}^{-2}$ and November with $\mathrm{N}=528$ ind. $\mathrm{m}^{-2}$. The mean annual biomass is $\overline{\mathrm{B}}=9.1$ g. $\mathrm{m}^{-2}$. The biomass shows temporal variations with a maximum of $B=26.0$ g. $\mathrm{m}^{-2}$ in August. Lower values were obtained in January with B $=1.2$ g.m $\mathrm{m}^{-2}$ and February with B $=1.3 \mathrm{~g} \cdot \mathrm{m}^{-2}$. The decrease in the density and biomass in winter is linked to the mortality of adults and the increase in spring to the recruitment of juveniles.

During the field experiment, we estimated the Surface of the burrow walls (Sb) varied from $\mathrm{Sb}=0.26 \mathrm{~m}^{2} \cdot \mathrm{m}^{-2}$ to 2.18 $\mathrm{m}^{2} \cdot \mathrm{m}^{-2}$ (mean $\mathrm{Sb}=0.75 \mathrm{~m}^{2} \cdot \mathrm{m}^{-2}$ ), and the Pumping rate $(\mathrm{Pr})$ from $\operatorname{Pr}=0.91$ to $7.71 . \mathrm{d}^{-1} \mathrm{~m}^{-2}$ (mean value $\operatorname{Pr}=2.71 . \mathrm{d}^{-1} \mathrm{~m}^{-2}$ ) (Fig. 2).

'The bioturbation activity of $H$. diversicolor is directly connected to the density of the population. H. diversicolor is capable of pumping large volumes of water into the sediment. The properties of the pumping action were studied

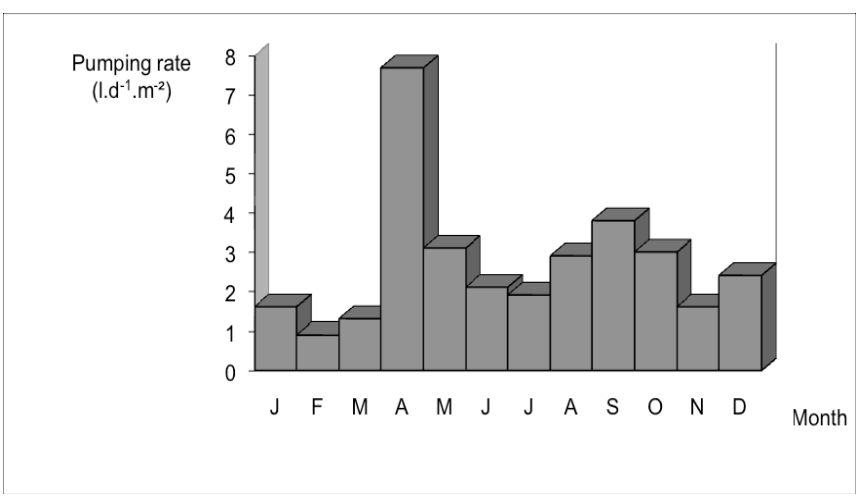

Fig. (2). Temporal variations in the Surface of burrows $\left(\mathrm{Sb}\right.$ in $\mathrm{m}^{2} \cdot \mathrm{m}^{-2}$ ) and Pumping rate ( $\operatorname{Pr}$ in $1 . \mathrm{d}^{-1} \cdot \mathrm{m}^{-2}$ mudflat surface) of Hediste diversicolor from the Loire estuary. 


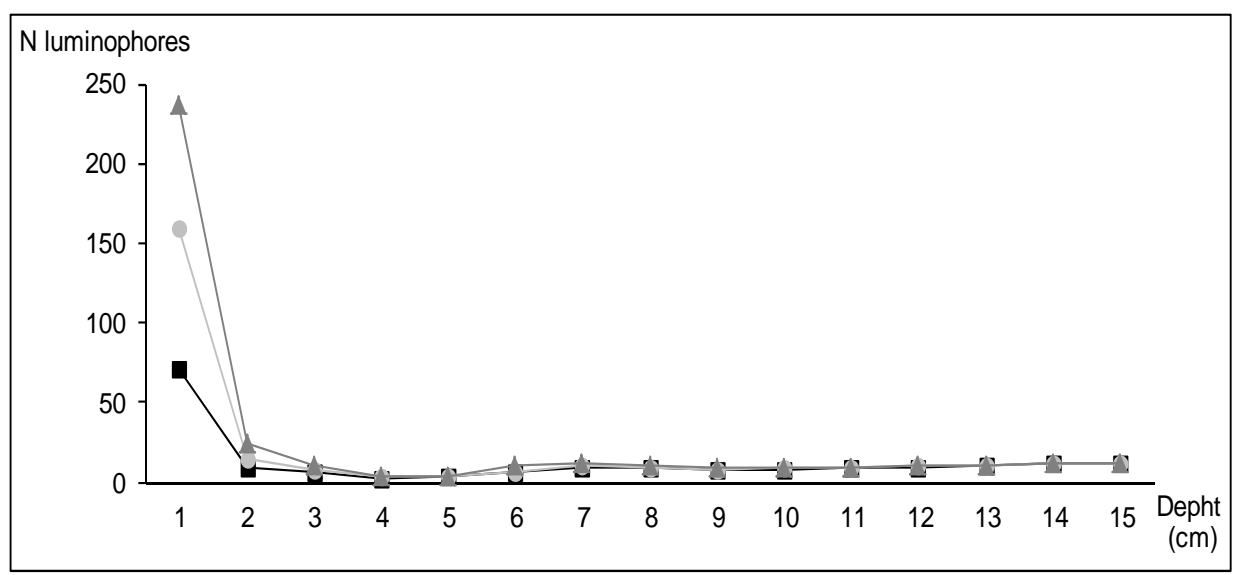

Fig. (3). Depth profiles $(\mathrm{cm})$ of the number of luminophores for the three cores containing Polychaete Hediste diversicolor from the Loire estuary.

in $H$. diversicolor [18]. It was found that $H$. diversicolor pumps about 401 of water per ml oxygen consumed. The pumping rate for a population of 2,400 ind. $\mathrm{m}^{-2}$ was estimated to $9.8 \mathrm{~m}^{3} \mathrm{~d}^{-1}$ or 10 times the whole water column daily. A natural population with 1,000 to 3,000 ind. $\mathrm{m}^{-2}$ may pass a volume corresponding to a water column of 3 to $9 \mathrm{~m}$ through their burrows each day [19].

\section{Laboratory Experiment}

Twelve individuals of $H$. diversicolor were necessary for the three experiments (four individuals in each core). They were measured and weighted before the experiment. Length varied from $\mathrm{L}=5.0$ to $7.5 \mathrm{~cm}$ and Weight from $\mathrm{W}=0.29$ to $0.73 \mathrm{~g}$. The depth profiles of luminophores for the three cores were different for each core (Fig. 3).

The gallery diffuser model was used to assess the core containing $H$. diversicolor. The pseudo-diffusive mixing (Db) in the region of intense burrowing activity was estimated. A significant difference of the bio-diffusion was observed between the three cores. The $\mathrm{Db}$ value varied from $\mathrm{Db}=1.2$ to $1.6($ mean $\mathrm{Db}=1.5)$. The non-local transport $(\mathrm{r})$ from the upper layers to the bottom of the tubes was calculated. The $r$ value varied from $r=1$ to 7.2 (mean $r=$ 4.3) (Table 1).

Table 1. Parameters of Bioturbation Activity of Hediste diversicolor from the Loire Estuary with the PseudoDiffusive Mixing (Db) and the non-local transport (r)

\begin{tabular}{|c|c|c|c|}
\hline Core & Db & r & Depth max \\
\hline \hline Core 1 & 1.6 & 7.2 & 11.5 \\
\hline Core 2 & 1.2 & 1.0 & 8.5 \\
\hline Core 3 & 1.6 & 4.6 & 9.5 \\
\hline Mean value & 1.5 & 4.3 & 9.8 \\
\hline
\end{tabular}

The results observed in the Loire estuary are among the highest values observed in the North Atlantic regions. The $\mathrm{Db}$ mean value is $\mathrm{Db}=1.5$ in the Loire estuary, and varies from $\mathrm{Db}=0.8$ in Scotland to 1.7 at Venice, Italy. The mean $\mathrm{r}$ value is $r=4.3$ in the Loire estuary, and varies from $r=2.45$ at Rostock, Germany to $\mathrm{r}=11.0$ at Aberdeen in the United Kingdom.

The optimal temperature of sediment reworking observed during the Nereis Park Experiment is $21^{\circ} \mathrm{C}$ for $H$. diversicolor. The optimal temperature of sediment reworking activity occurred at $13^{\circ} \mathrm{C}$ for Neanthes virens in the Saint Lawrence Estuary, Canada [20]. N. virens is a cold stenothermic species and $H$. diversicolor a eurythermic species [21]. There is a positive relationship between $\mathrm{Db}$ and temperature. On the contrary, there is a negative relationship between $\mathrm{Db}$ and biomass. It seems that small individuals are more efficient reworkers than big ones. Small animals are more active on the surface. The highest bio-diffusion due to $H$. diversicolor was shown by Mermillod-Blondin et al. [16, 17] in comparison with benthic invertebrates as Cerastoderma edule and Corophium volutator. In the case of $H$. diversicolor, the biogeochemical nature of the sediment depends on the balance of metabolite production rates, removal and oxidation due to $H$. diversicolor bioturbation activity [10].

The nereid $H$. diversicolor constructs burrows and is considered a gallery diffuser [22]. Gallery-diffusor animals produce particle diffusion in the layer with very dense gallery systems and a bio-transport (non-local transport) at the end of the burrows [13]. The transport of sediment from the deeper sediment to the sediment-water interface represents a mechanism whereby organic matter can be recycled by animals. $H$. diversicolor inhibits anaerobic metabolism and alters sediment $\mathrm{S}$ cycles, although to various extents. A study of behavioural response (ventilation rate, duration of ventilation, length of pauses...) of three closely related nereid polychaetes (H. diversicolor, $N$. succinea and $N$. virens) to various levels of sulphide exposure did not show much variation under HS exposure for $H$. diversicolor. The only significant response was a decreased duration of rest periods at high HS concentration. $H$. diversicolor removed most HS from the burrow in less than 10 min due to the high ventilation rate of this species [23].

To conclude, the density and the biomass of $H$. diversicolor populations largely controlled the amount of sediment reworked. The classification of Pearson \& Rosenberg [24] using four modes of functional traits (feeding mode, mobility mode, degree of mobility and mode 
of feeding habit) aimed to link marine benthic community and benthic habitats. Pearson [25] shows that our knowledge is good enough to partition the benthic infauna into functional groups, which are then used to explain changes along organic enrichment gradients. Infauna (bioturbation and grazing) benthic microalgae and pore-water nutrients appear to be key components in a biogeochemical network in shallow water of estuarine systems [26]. The redistribution of particles by $H$. diversicolor occurs in bouts of activity (every $100 \mathrm{~min}$ ) that are associated with burrow construction, maintenance and the repositioning of the upper region of the burrow during the establishment of new connections with the sediment-water interface [27]. There was a significant relationship between the bio-volume of macrobenthos and the diffusion coefficient of surface sediment, suggesting that the bio-volume of macrobenthos could be used as an indicator to predict the bioturbation capacity of estuarine sediment [28].

\section{CONFLICT OF INTEREST}

None declared.

\section{ACKNOWLEDGEMENTS}

Nereis Park Experiment is a tribute to Gaston Desrosiers, Professor at the University of Quebec at Rimouski, for his work on Nereis virens.

\section{REFERENCES}

[1] Scaps P. A review of the biology, ecology and potential use of the common ragworm Hediste diversicolor (O.F. Müller) (Annelida: Polychaeta). Hydrobiologia 2002; 470: 203-18.

[2] Marchand J. Bionomie benthique de l'estuaire de la Loire. I: Observations sur l'estran maritime de la mer à Cordemais. Revue Travaux Institut des Pêches Maritimes 1972; 36: 47-67.

[3] Marchand J, Gascuel D. Seasonal dynamics of the zoobenthic communities in the mesohaline zone of the Loire estuary (France). Hydrobiologia 1988; 160: 129-39.

[4] Robineau B. Caractérisation des peuplements macrozoobenthiques de l'estuaire de la Loire. Vie et Milieu 1987; 37: 67-76.

[5] Gillet P. Biomasse, production et dynamique des populations de Nereis diversicolor (annélide polychète) de l'estuaire de la Loire (France). Oceanologica Acta 1990; 13: 361-71.

[6] Gillet P, Torresani S. Structure of the population and secondary production of Hediste diversicolor (O.F. Müller, 1776), (Polychaeta, Nereididae) in the Loire estuary, Atlantic coast, France. Estuar Coast Shelf Sci 2002; 56: 621-8.

[7] Durou C, Smith BD, Roméo M, et al. From biomarkers to population response in Nereis diversicolor: assessment of stress in estuarine ecosystems. Ecotoxicol Environ Saf 2007; 66: 402-11.

[8] Gillet P, Mouloud M, Durou C, Deutsch B. Response of Nereis diversicolor population (Polychaeta, Nereididae) to the pollution impact - Authie and Seine estuaries (France). Estuar Coast Shelf Sci 2007; 76: 201-10.

[9] Denis L, Boust D, Thouvenin B, et al. Dynamic diagenic modelling and impacts of biota. Amiard-Triquet C, PS. Rainbow. Eds. In
"Environmental assessment of estuarine ecosystems: a case study". USA: CRC Press Taylor and Francis 2009.

[10] Banta GT, Holmer M, Jensen MH, Kristensen E. Effects of two polychaete worms Nereis diversicolor and Arenicola marina, on aerobic and anaerobic decomposition in a sandy marine sediment. Aquatic Microbial Ecol 1999; 19: 189-204.

[11] Kristensen E. Impact of polychaetes (Nereis spp. and Arenicola marina) on carbon biogeochemistry in coastal marine sediment. Geochem Trans 2001; 2: 17-30.

[12] Biles CL, Paterson DM, Ford RB, Solan M, Raffaelli DG. Bioturbation ecosystem functioning and community structure. Hydrol Earth Syst Sci 2002; 6: 999-1005.

[13] François F, Gerino M, Stora G, Durbec JP, Poggiale JC. A functional approach to sediment reworking by gallery forming macrobenthic organisms: modelling and applications with the polychaete Nereis diversicolor. Mar Ecol Prog Ser 2002; 229: 12736.

[14] Fernandes S, Meysman FJR, Sobral P. The influence of $\mathrm{Cu}$ contamination on Nereis diversicolor bioturbation. Mar Chem 2006; 102: 148-58.

[15] Fernandes S, Sobral P, Costa MH. Nereis diversicolor effect on the stability of cohesive intertidal sediments. Aquat Ecol 2006; 40: 567-79.

[16] Mermillod-BF, François-CF, Rosenberg R. Biodiversity of benthic invertebrates and organic matter processing in shallow marine sediments: an experimental study. J Exp Mar Biol Ecol 2005; 315 : 187-209.

[17] Mermillod-BF, Rosenberg R, François-CF, Norling K, Mauclaire $\mathrm{L}$. Influence of bioturbation by three benthic infaunal species on microbial communities and biogeochemical processes in marine sediment. Aquat Microbiol Ecol 2004; 36: 271-84.

[18] Riisgard HU. Suspension feeding in the polychaete Nereis diversicolor. Mar Ecol Prog Ser 1991; 70: 29-37.

[19] Koretsky C, Meile MC, Van Cappellen P. Quantifying bioirrigation using ecological parameters: a stochastic approach. Geochem Trans 2002; 3: 17-30.

[20] Ouellette D, Desrosiers G, Gagne JP. et al. Effects of temperature on in vitro sediment reworking processes by a gallery biodiffusor, the polychaete Neanthes virens. Mar Ecol Prog Ser 2004; 266: 18593.

[21] Kristensen E. Factors influencing the distribution of nereid polychaetes in Danish coastal waters. Ophelia 1988; 29: 127-40.

[22] Christensen B, Vendel A, Kristensen E. Carbon and nitrogen fluxes in sediment inhabited by suspension-feeding (Nereis diversicolor) and non suspension-feeding (N. virens) polychaetes. Mar Ecol Prog Ser 2000; 192: 203-17.

[23] Miron G, Kristensen E. behavioural response of three nereid polychaetes to injection of sulphide inside burrows. Mar Ecol Prog Ser 1993; 101: 147-55.

[24] Pearson TH, Rosenberg, R. Feast and famine: structuring factors in marine benthic communities. In: Gee JHR, Giller PR Eds. The $27^{\text {th }}$ symposium of the British Ecological Society, Aberystwyth. Oxford: Blackwell Scientific Publications 1986; pp. 373-95.

[25] Pearson TH. Functional group ecology in soft-sediment marine benthos: the role of bioturbation. Oceanogr Mar Biol Annu Rev 2001; 39: 233-67.

[26] Engelsen A, Sunbäck K, Hulth S. Links between bottom-water anoxia, the polychaete Nereis diversicolor, and the growth of green-algal mats. Estuar Coast 2010; 33: 1365-76.

[27] Schiffers K, Teal LR, Travis JMJ, Sola M. An open source simulation model for soil and sediment bioturbation. Plos One 2011; 6: e28028

[28] Qin XB, Sun HW, Wu JZ, Wang RN, Sun TH. Bioturbation of macrobenthos on estuarine sediment. Ying Yong Sheng Tai Xu Bao 2010; 21: 458-63.

This is an open access article licensed under the terms of the Creative Commons Attribution Non-Commercial License (http://creativecommons.org/ licenses/by-nc/3.0/), which permits unrestricted, non-commercial use, distribution and reproduction in any medium, provided the work is properly cited. 